\title{
Incorporação do Objeto em Sateré-Mawé
}

Dulce do Carmo Franceschini ${ }^{1}$

\section{Resumo}

Neste artigo é mostrado que a incorporação nominal em Sateré-Mawé resulta de um processo de composição envolvendo um nome, inalienável ou alienável, e um verbo transitivo, e que as bases lexicais resultantes são respectivamente télicas (classe I) ou atélicas (classe II). É também mostrado que nomes que se referem a entidades inanimadas ou animadas não humanas se incorporam mais facilmente do que nomes que se referem a seres humanos.

Palavras-chave: Incorporação nominal, composição, transitividade, telicidade, unidade semântica.

\begin{abstract}
In this article it is shown that nominal incorporation in Sateré-Mawé results from a compositional process involving a noun, inalienable or alienable, and a transitive verb, and that the resulting lexical bases are respectively telic (class I) and atelic (class II). It is also shown than nouns referring non-human inanimate or animate entities are more often incorporated than nouns referring to human beings.
\end{abstract}

Keywords: Nominal incorporation, composition, transitivity, telicity, semantic unit.

\section{Introdução}

Neste artigo, apresentamos uma descrição da incorporação do objeto em Sateré-Mawé2. A incorporação do objeto é apenas um dos tipos de uma categoria mais ampla, a incorporação nominal (Payne 1997:222).

Segundo Creissels (2006:14), morfologicamente a incorporação é um mecanismo de composição pelo qual a combinação de um verbo e de um nome dá origem a uma única palavra com o status de verbo. Do ponto de vista sintático, a incorporação não apresentaria sempre o mesmo efeito sobre a valência do verbo que incorpora um nome.

\footnotetext{
${ }^{1}$ Universidade Federal de Uberlândia; Laboratório de Línguas Indígenas, Universidade de Brasília. ${ }^{2}$ Os Sateré-Mawé vivem, há mais de 400 anos, na região do Tapajós-Madeira (Baixo-Amazonas). O território Sateré-Mawé, chamado Andirá-Marau, foi demarcado pela FUNAI em 1982 e compreende 788.528 hectares situados entre os estados do Pará e do Amazonas. A população Sateré-Mawé é de cerca de 8.700 pessoas, que vivem em sua maioria na área indígena. A língua Sateré-Mawé é classificada como único membro da família Mawé pertencente ao tronco Tupí (Rodrigues 1984/85). Essa língua é falada por quase todos os Sateré-Mawé que vivem na região dos rios Andirá e Marau; no entanto, já se encontra bastante enfraquecida na região do rio Waikurapá e nas comunidades indígenas que se localizam na boca dos rios Andirá e Marau.
} 
Como Creissels, Lazard (1994:15) considera a incorporação de um nome à forma verbal um tipo de composição, que tem por finalidade criar uma forma verbal predicativa. $\mathrm{O}$ nome incorporado formaria, então, com o lexema verbal uma unidade semântica (nova base verbal) e perderia sua função actancial (gramatical). É o que se pode observar em Sateré-Mawé.

\section{Formação de novas bases verbais}

Em Sateré-Mawé, a incorporação do objeto serve para formar novas bases verbais que apresentam em sua construção a incorporação de um nome e funcionam como predicado de um enunciado, como mostra o exemplo (2) abaixo:

Verbo sem incorporação do objeto ${ }^{3}$ :

$$
\begin{aligned}
& \text { e-ti-Pauka ase } i \quad \text { e-wawori } \\
& \text { 2-AT.1-matar vovô } \quad \mathrm{R} \text { - jabuti } \\
& \text { 'você matou o jabuti do vovô' }
\end{aligned}
$$

Verbo com incorporação do objeto:

$$
\begin{aligned}
& \text { e-he-wawori-Pauka aseßi } \\
& \text { 2-Aт.2-jabuti-matar vovô } \\
& \text { 'você matou jabuti do vovô' }
\end{aligned}
$$

Enquanto que, no exemplo (1), o verbo apresenta uma base simples, /Rauka/ 'matar', e /wawori/ é o núcleo do sintagma nominal /ase'i ewawori/ em função de objeto, no exemplo (2), o verbo apresenta uma base composta, /wawori'auka/ 'matar jabuti', sendo que o nome incorporado ao verbo / wawori/ não desempenha mais a função objeto no enunciado. Essa função gramatical é assumida pelo nome /ase?i/, ou seja, pelo possuidor do termo incorporado.

Pode-se dizer que a incorporação do objeto em Sateré-Mawé corresponde ao tipo II da classificação proposta por Marianne Mithun, a qual é chamada manipulação de caso. Segundo Mithun (1984:856):

type II advances an oblique argument into the case position vacated by the IN (incorporated noun). When a transitive verb incorporates its direct object, then an instrumental, location,

\footnotetext{
${ }^{3}$ Abreviaturas usadas: at. $1=$ voz ativa $1 ;$ at. $2=$ voz ativa $2 ;$ med $=$ voz média; $r=$ relacional; refl $=$ reflexivo; 1 = primeira pessoa; $2=$ segunda pessoa; $3=$ terceira pessoa; 1 excl. $=$ primeira pessoa exclusiva; 1 incl. $=$ primeira pessoa incluiva; $>=$ maior do que.
} 
or possessor may assume the vacated object role. When an intransitive verb incorporates its subject, another argument may be advanced to subject status.

Além da incorporação do objeto, a manipulação de caso de Mithun faz referência à incorporação do sujeito. Em Sateré-Mawé, no entanto, não temos exemplos de incorporação do sujeito. Esse tipo de incorporação é mais raro nas línguas do mundo, enquanto que a incorporação do objeto é bem mais comum e pode ser observada em muitas línguas indígenas da América. Segundo Aryon Dall'Igna Rodrigues (1951), a incorporação do objeto é um dos tipos de composição que encontramos em Tupí Antigo ou Tupinambá:

$\mathrm{Na}$ incorporação do objeto, o tema do substantivo precede o tema verbal transitivo. Se o substantivo incorporado estiver na forma absoluta, ou se for inconjugável, ou se se empregar indeterminadamente, o todo resultante será um verbo intransitivo; em caso contrário, i. é, se for conjugável, não estando na forma absoluta, será um verbo transitivo. (Rodrigues 1951:8).

Os verbos compostos em Sateré-Mawé apresentam a mesma estrutura que os verbos compostos do Tupinambá, ou seja, substantivo + base verbal. No entanto, em relação à valência da base verbal composta formada por incorporação, ao passo que em Tupinambá esta pode ser a mesma da base simples (transitiva) ou pode diminuir, resultando, então, em um verbo intransitivo, dependendo do nome incorporado ser relativo ou absoluto, em Sateré-Mawé a nova base verbal continua transitiva.

\section{A construção resultante de incorporação em Sateré-Mawé}

A incorporação do objeto direto em Sateré-Mawé resulta em uma construção cujo objeto pode ser interpretado como sendo o possuidor do nome incorporado, como se pode observar no exemplo (4) abaixo:

$$
\begin{aligned}
& \text { paini } \emptyset \text {-tu'-nuך kurum } \emptyset \text {-poha } \\
& \text { pajé 3-Aт.1-fazer menino R-remédio } \\
& \text { 'o pajé fez o remédio do menino' }
\end{aligned}
$$

$$
\begin{array}{lll}
\text { paini } & \emptyset \text {-ti-pohan-nuy } & \text { kurum } \\
\text { pajé } & \text { 3-At.1-remédio-fazer } & \text { menino } \\
\text { 'o pajé fez remédio do menino' } &
\end{array}
$$

\footnotetext{
${ }^{4} \mathrm{O}$ morfema indicador da voz ativa 1 /-ti-/ realiza-se como [-tu-] quando precede sílaba que apresenta a vogal $[u]$. Trata-se de um fenômeno de assimilação regressiva.
} 
No exemplo (3), a posição de objeto é ocupada pelo sintagma nominal /kurum pohay/ 'o remédio do menino'; já no exemplo (4), a posição de objeto é ocupada pelo determinante do sintagma nominal, ou seja, pelo seu possuidor 'o menino', uma vez que o núcleo do sintagma nominal ao ser incorporado ao verbo perde sua função actancial.

A incorporação nominal em Sateré-Mawé caracteriza-se também por não afetar a valência do verbo, isto é, o verbo derivado por composição continua transitivo direto. Essas bases compostas, no entanto, assim como as bases transitivas simples, podem derivar por meio da prefixação do morfema -we- 'reflexivo', bases verbais intransitivas, conforme mostram os exemplos (5) a (8) abaixo:

Predicado com base verbal simples derivada:

paini $\emptyset-t u^{5}-(w) e-n u \eta$

pajé 3-MED-REFL-fazer

'o pajé se fez $>$ se transformou'

(6) $e-r e-(w) e-3 a u k a$

2-MED-REFL-matar

'você se matou / se suicidou'

Predicado com base verbal composta derivada:

(7) paini $\emptyset$-tu-(w)e-pohan-nuך

pajé 3-MED-REFL-remédio-fazer

'o pajé se fez remédio / fez remédio para si mesmo'

(8) e-re-(w)e-wawori-Pauka

2-MED-REFL-jabuti-matar

'você se matou jabuti/ matou jabuti para si mesmo'

Enquanto que os exemplos (5) e (6) apresentam bases verbais intransitivas derivadas de bases transitivas simples e indicam processos, nos quais o participante indiciado no verbo assume ao mesmo tempo os papéis semânticos de agente e paciente do processo que realiza, os exemplos (7) e (8), que apresentam bases verbais intransitivas derivadas de verbos transitivos

\footnotetext{
${ }^{5}$-tu- é uma variante do morfema -to-, que indica a voz média em Sateré-Mawé e não deve ser confundido com o - $t u$-, variante do morfema - $t i$-, indicador da voz ativa 1.
} 
compostos, indicam que o participante indiciado no verbo assume o papel semântico de agente e de beneficiário da ação que realiza. Esses são dois dos valores semânticos da voz média em Sateré-Mawé. ${ }^{6}$

Do ponto de vista semântico, observa-se que nem todos os nomes são passíveis de incorporação em Sateré-Mawé. A incorporação nominal responde à seguinte hierarquia: nomes que se referem a entidades inanimadas ou animadas não humanas se incorporam mais facilmente do que nomes que se referem a seres humanos. Segundo Donna B. Gerdts (1998:86), essa hierarquia reflete uma tendência geral, através das línguas, de nomes mais animados e humanos serem mais centrais no discurso e, portanto, menos passíveis de serem incorporados.

Pode-se dizer que, embora os predicados com verbos compostos apresentem o mesmo significado referencial que os predicados com verbos simples, do ponto de vista pragmático-discursivo, eles nos mostram diferentes formas de apreensão do evento. Enquanto que nos enunciados com predicados simples, o termo que se refere à entidade possuída apresenta maior grau de topicalidade no discurso que o termo que se refere ao possuidor, nos enunciados com predicados compostos, é o termo que se refere ao possuidor que apresentará maior grau de topicalidade. Não há, portanto, do ponto de vista pragmático-discursivo, uma correspondência entre os predicados que apresentam incorporação e os que não apresentam, pois quando incorporado, o nome apresenta menor topicalidade no discurso.

\section{Classes de verbos - classes de nomes e incorporação}

Os verbos ativos, ou seja, os transitivos diretos, assim como os nomes, organizam-se em diferentes classes em Sateré-Mawé. Para compreender melhor a composição verbal nessa língua é necessário levar em consideração essa organização do seu sistema verbal e nominal.

Em Sateré-Mawé, os verbos de processo organizam-se em duas classes: verbos ativos e médios, podendo esses últimos ser intransitivos ou transitivos indiretos. Enquanto que os verbos ativos indicam processos que se realizam a partir de um agente, que é o participante indiciado no verbo (primeiro actante), sobre uma entidade externa que é o paciente, representada pelo segundo actante (objeto direto), os verbos médios indicam processos que se realizam a partir do participante indiciado no verbo (primeiro actante), e que o afetam de alguma maneira, seja de forma direta ou indireta.

\footnotetext{
${ }^{6}$ Sobre os valores da voz média em Sateré-Mawé, ver Franceschini (2007).
} 
No verbo, a voz média é marcada pelo índice relacional -re- $\sim-$ to- $^{7}$. Já a voz ativa é marcada seja pelo índice relacional $-t i-\sim-i-\sim-\emptyset_{-}{ }^{8}$, classe I, seja pelo índice $-h(e)-$, classe II. Esses dois morfemas da voz ativa servem para diferenciar bases verbais ativas que apresentam distintos aspectos lexicais: télico (classe I) e atélico (classe II), como mostram os exemplos abaixo:

$$
\begin{aligned}
& \text { wa- ti-tek pay (Classe I) } \\
& \text { 1INCL-AT.1-cortar paca } \\
& \text { 'nós (incl.) cortamos a paca' }
\end{aligned}
$$

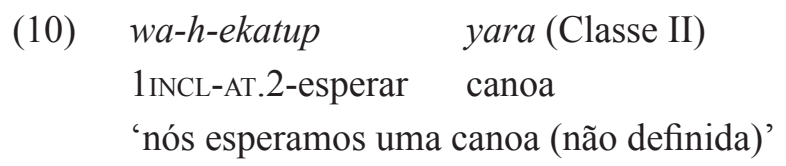

A telicidade nos verbos ativos está relacionada à forma como o processo afeta o referente do segundo actante. Os verbos ativos télicos denotam processos delimitados em sua realização e que atingem o referente do segundo actante como um todo e diretamente. Pode-se dizer que os predicados ativos télicos determinam a delimitação do referente do objeto direto, conforme mostram os exemplos (11) a (13) abaixo:

(11) wa-ti-Rauka moi 'nós (incl.) matamos a cobra'

(12) wa-ti-koi mani 'nós (incl.) plantamos a mandioca'

(13) a-ti-koho sokpe 'eu lavei a roupa'

Nos exemplos de (11) a (13) acima, os processos denotados pelos verbos são apreendidos globalmente, sendo o referente do segundo actante afetado diretamente e completamente pelos mesmos. Os processos denotados pelos verbos dessa classe só podem ser considerados como realizados se atingirem seu término, isto é, esses verbos apresentam uma delimitação inerente e determinam a forma de apreensão do referente do objeto direto ( + definido), e ao se realizarem dão origem a uma nova situação, ou seja, a um estado resultativo: a cobra está morta; a mandioca está plantada; a roupa está lavada.

Já os verbos ativos atélicos expressam processos que não precisam atingir seu final para serem considerados como realizados, ou seja, que podem

\footnotetext{
${ }^{7}$ Variantes em distribuição complementar no paradigma de pessoa.

${ }^{8}$ Tanto as variantes do índice relacional da classe I dos verbos ativos, quanto as variantes do morfema da voz média, ocorrem de forma regular e em distribuição complementar no paradigma pessoal.
} 
ser considerados como realizados desde que iniciam. Denotam processos que não são apreendidos globalmente, seja pelo fato de não terem um fim prédeterminado em si mesmo, ou pelo fato de não afetarem inteiramente ou diretamente o referente do segundo actante, conforme mostram os exemplos de (14) a (16) abaixo:

(14) wa-h-i:n mohi:t 'nós (incl.) sentimos o cheiro de/da flor'

(15) wa-he-wain kurum 'nós aconselhamos o rapaz'

(16) uru-h-anti ini 'nós (excl.) amarramos a rede'

Os exemplos (14) e (15) denotam processos que não apresentam uma delimitação em si mesmos, que não são mensuráveis em sua realização: "cheirar/sentir o cheiro" e "aconselhar"; e que não afetam diretamente e completamente o referente do segundo actante: em (14) o processo não afeta diretamente a flor, mas apenas algo que faz parte da flor, isto é, o cheiro que ela exala; e nem completamente, pois nem todo cheiro que a flor exala é sentido $;$ em (15), igualmente, o processo não atinge diretamente o participante representado pelo segundo actante e nem completamente. Já o exemplo (16) denota um processo que afeta diretamente o referente do segundo actante, a rede, mas que não o afeta inteiramente, pois a interpretação desse enunciado é "amarrar/prender apenas os punhos da rede".

Os nomes em Sateré-Mawé também podem ser classificados em duas grandes classes, a dos nomes inalienáveis e a dos alienáveis. Enquanto que os nomes inalienáveis apresentam no sintagma possessivo o índice relacional $-i$ $\sim-\emptyset$-, os nomes alienáveis apresentam o índice $-h e-\sim-e-$, conforme mostram os exemplos abaixo:

Nomes da classe I - inalienáveis:

u-i-pohan 'meu remédio'

$e-\emptyset-t \dot{t} \quad$ 'tua mãe'

Nomes da classe II - alienáveis:

u-he-wawori 'meu jabuti'

uru-e-pi:ra 'nosso (excl.) peixe'

A incorporação de nomes da classe I ou da classe II nos verbos ativos resultará na formação de verbos compostos de diferentes classes aspectuais. Enquanto que a formação de bases verbais compostas com nomes alienáveis

\footnotetext{
${ }^{9}$ Essa explicação foi dada por um falante da língua analisada e condiz com a definição de aspecto atélico.
} 
resulta sempre em bases verbais compostas atélicas, ou seja, da classe II dos verbos ativos, a incorporação de nomes inalienáveis a uma base ativa resultará sempre na formação de uma base composta télica (classe I dos verbos ativos). Ou seja, as bases verbais télicas (classe I) ao formarem uma base verbal composta com nomes alienáveis, passam a funcionar como bases atélicas (cf. exs. $21>22 / / 23>24$ ), enquanto que, ao formarem uma base verbal composta com nomes inalienáveis, continuarão a funcionar como télicas (cf. exs. $27>28$ // $29>30$ ); o mesmo ocorre com bases verbais atélicas: ao serem compostas com nomes alienáveis, produzirão bases compostas atélicas (cf. ex. $25>26$ ), enquanto que, ao serem compostas com nomes inalienáveis, produzirão bases compostas télicas (cf. ex. $31>32$ ).

(a) Nome alienável + base verbal télica ou atélica $>$ base verbal composta atélica:
(21) e-ti-koi ase'i e-mani
'você plantou a mandioca do vovô'
(22) e-he-mani-koi
ase' $i$
'você plantou mandioca do vovô'
e-tu- ?u kurum e-pira
'você comeu o peixe do menino'
(24) e-he-pira-?u
kurum
'você comeu peixe do menino'
(25) a-h-ekatup mana e-iara
'eu espero a canoa da mana'
(26) a-he-iara-ekatup mana 'eu espero canoa da mana.'

(b) Nome inalienável + base verbal télica ou atélica $>$ base verbal composta télica:
(27) a-tu-nuך ?iat
paulo
(29) a-ti-petek hirokat po 'eu bati na mão da criança'
(31) a-h-ewain kurum $\emptyset$-ty 'eu aconselho a mãe do menino'

(28) a-ti-Piat-nu円

'eulo fiz casa do Paulo'
(30) a-ti-po-petek
'eu bati mão da criança'
(32) a-ti-ty-ewain kurum 'eu aconselho mãe do menino'

Nos exemplos (21) e (23), têm-se bases verbais télicas marcadas na morfologia do verbo pelo morfema -ti-, e, no exemplo (25), uma base verbal atélica, marcada pelo morfema $-h(e)$-; as bases simples dos exemplos (21) e (23), ao formarem bases compostas com nomes alienáveis, passam a apresentar um aspecto semântico atélico, o qual será indicado pelo morfema - $h($ e)-, conforme mostram os exemplos (22) e (24), e a base atélica, ao formar uma base composta com um nome alienável, permanece atélica, conforme mostra o exemplo (26) acima. 
Já nos exemplos de (27) a (32), a derivação se faz a partir de nomes inalienáveis, portanto, as bases derivadas de bases simples télicas ou atélicas resultam em bases compostas télicas que são marcadas pelo morfema -ti-, presente nos predicados dos exemplos (28), (30) e (32).

Essa correlação entre aspecto atélico e alienabilidade e aspecto télico e inalienabilidade pode ser melhor compreendida a partir do que nos diz Klimov a respeito da posse alienável e inalienável.

Segundo Klimov (1974:23), nas línguas ativas, o que parece ser o caso da língua em estudo, a posse expressaria uma relação do tipo partetodo ou não. A relação do tipo parte-todo faz referência a uma relação que é apreendida como sendo essencial e necessária entre o possuidor e o possuído, sendo que o possuído (à parte) forma um todo com o possuidor, é parte inerente de seu possuidor. Já a relação de posse que não expressa uma relação do tipo parte-todo faz referência a uma relação que não é essencial, que se estabelece circunstancialmente entre um possuidor e o que é possuído, cada um mantendo sua individualidade.

Em Sateré-Mawé, pode-se dizer que a posse inalienável é do tipo partetodo, enquanto que a possessão alienável não o é. Isto é, os referentes dos nomes alienáveis, em uma relação possessiva ou genitiva, são apreendidos como entidades que não são ligadas de forma inerente ao seu possuidor, ou seja, que não formam um todo com seu possuidor; já os referentes dos nomes inalienáveis são apreendidos como parte integrante do possuidor, isto é, formando um todo com ele.

Os nomes alienáveis e inalienáveis, por apresentarem diferentes tipos de relação com o termo que se refere ao possuidor, quando incorporados ao verbo, farão com que este apresente diferentes formas de relação com o referente do objeto, o possuidor, e, em consequência, diferentes aspectos lexicais.

As bases verbais compostas formadas com nomes alienáveis apresentam um aspecto atélico, pois o referente do objeto direto (o possuidor) não é afetado diretamente e nem completamente pelo processo, uma vez que não é apreendido como parte inerente do referente do termo incorporado (o possuído), conforme mostram os exemplos (22), (24) e (26); já as bases compostas formadas pela incorporação de nomes inalienáveis são télicas, uma vez que o referente do objeto direto (o possuidor) será afetado inteiramente e diretamente pelo processo, uma vez que é apreendido como parte inerente do referente do termo incorporado 
no verbo (o possuído), conforme mostram os exemplos (28), (30) e (32). Essa parece ser a forma de apreensão dos eventos denotada pelos verbos compostos em Sateré-Mawé.

Torna-se, portanto, evidente a relação entre alienabilidade e atelicidade e entre inalienabilidade e telicidade em Sateré-Mawé. Essa relação também é perceptível nas formas morfológicas empregadas na língua para marcar essas categorias semânticas; em efeito, a alienabilidade dos nomes e a atelicidade dos verbos ativos são marcadas nos sintagmas possessivos e verbais por formas bastante semelhantes: $-h(e)-\sim-e-\mathrm{e}-h(e)-$, respectivamente; e a inalienabilidade dos nomes e telicidade dos verbos pelas formas $-i-\sim-\emptyset$ - e $-t i-\sim-i-\sim-\emptyset$, respectivamente.

\section{Considerações finais}

Neste artigo procuramos mostrar que a composição verbal em SateréMawé resulta da incorporação no verbo do nome que ocupa a posição objeto no enunciado, formando, assim, com a base verbal uma nova unidade lexical. A posição objeto passa, então, a ser ocupada pelo determinante do nome incorporado, ou seja, o nome que faz referência ao seu possuidor, não ocorrendo, portanto, uma alteração na valência da base verbal que permanece transitiva.

Do ponto de vista semântico, a incorporação nominal em Sateré-Mawé é controlada por uma hierarquia, uma vez que nomes que se referem a entidades inanimadas ou animadas não humanas se incorporam mais facilmente do que nomes que se referem a seres humanos. De fato, nomes que se referem a seres humanos sempre apresentam mais importância no discurso do que nomes que se referem a seres inanimados, o que restringe suas possibilidades de serem incorporados, já que a incorporação representa também uma perda de topicalidade.

Mostrou-se também que a incorporação de nomes inalienáveis e alienáveis no verbo resulta em bases compostas ativas de diferentes classes aspectuais, ou seja, na formação de bases compostas télicas (classe I) ou atélicas (classe II), respectivamente. O que evidencia a existência de uma correlação, por um lado, entre inalienabilidade e telicidade, e por outro lado, entre alienabilidade e atelicidade. 


\section{Referências}

Comrie, Bernard. 1976. Aspect. Cambridge: Cambridge University Press.

Creissels, Denis. 2006. Syntaxe générale - une introduction typologique 2. Paris: Lavoisier/Hermes Science.

Franceschini, Dulce. 1999. La langue sateré-mawé: description et analyse morphosyntaxique. Paris, França, Thèse de doctorat, Université Denis Diderot, Paris VII.

Franceschini, Dulce. 2007. Valores da voz média em Sateré-Mawé. In: Ana Suelly A.C. Cabral; Aryon D. Rodrigues (orgs.) Linguas e Culturas Tupí, vol.1. Campinas: Editora Curt Nimuendajú, p. 309-315.

Gerdts, Donna B. Incorporation. 1998. In: A. Spencer and A. Zwicky (eds.), The Handbook of Morphology. Oxford: Basil Blackwell, p. 84-100.

Klimov, G.A. 1974. On the character of Languages of Active Tipology. Linguistics 131:11-25.

Lazard, Gilbert. 1994. L'actance. Paris: PUF.

Mithun, Marianne. 1984. The evolution of noun incorporation. Languag. 60:4, p. 847-894.

Payne, Thomas. 1997. Describing morphosyntax. Cambridge: Cambridge University Press.

Rodrigues, Aryon Dall'Igna. 1951. A composição em Tupí. Separata de Logos, ano VI, n. 14. Curitiba.

Rodrigues, Aryon Dall’Igna. 1984/85. Relações Internas na Família Linguística Tupí-Guarani. Em: Revista de Antropologia 27/28:33-53. 
